\title{
Science and technology in Mexico
}

\section{Arturo Menchaca-Rocha}

\author{
Mexico's economy is doing relatively well, but its science is chronically under-supported and the country's \\ technological dependence is increasing rapidly. Without a strong science and technology base, the \\ nation's future is at risk.
}

T wo hundred years ago Mexico declared independence from Spain. Shortly before, the German naturalist Alexander von Humboldt visited the country and described the quality of its academic community as superior to any other in Latin America. On his way back to Europe he brought samples of what a local engineer, Andrés Manuel del Río, claimed to be a new chemical element. Now known as vanadium, it is a highly appreciated material used in metallurgy and electronics. Unfortunately, the samples got lost in the Paris laboratory hired to confirm the claim. Mexico lost its chance for what would have been its first major contribution to modern science.

The half century of political and armed struggle that followed Humboldt's visit distanced the country from the scientific progress occurring in Europe and the USA. Only at the dawn of the twentieth century did Mexican academia show signs of recovery, marked by the creation of the National University of Mexico (UNM) in 1910. A few months later the Mexican Revolution began, postponing the birth of professional science for Mexico until 1929 when UNM achieved autonomy. That same year UNAM, as it is has been known since, established the first scientific research institutes in biology and geology, together with an astronomical observatory. Soon other research institutes and schools followed, laying the foundation for most of today's science and technology institutions in Mexico. The conflicts in Europe in the 1940s brought to the country highly skilled intellectuals, which gave extra impulse to the scientific development. The postwar economic bonanza further contributed to a rapid economic expansion illustrated by the construction of a new UNAM campus at the southern end of Mexico City, now identified by its mosaic-walled library (Fig. 1).

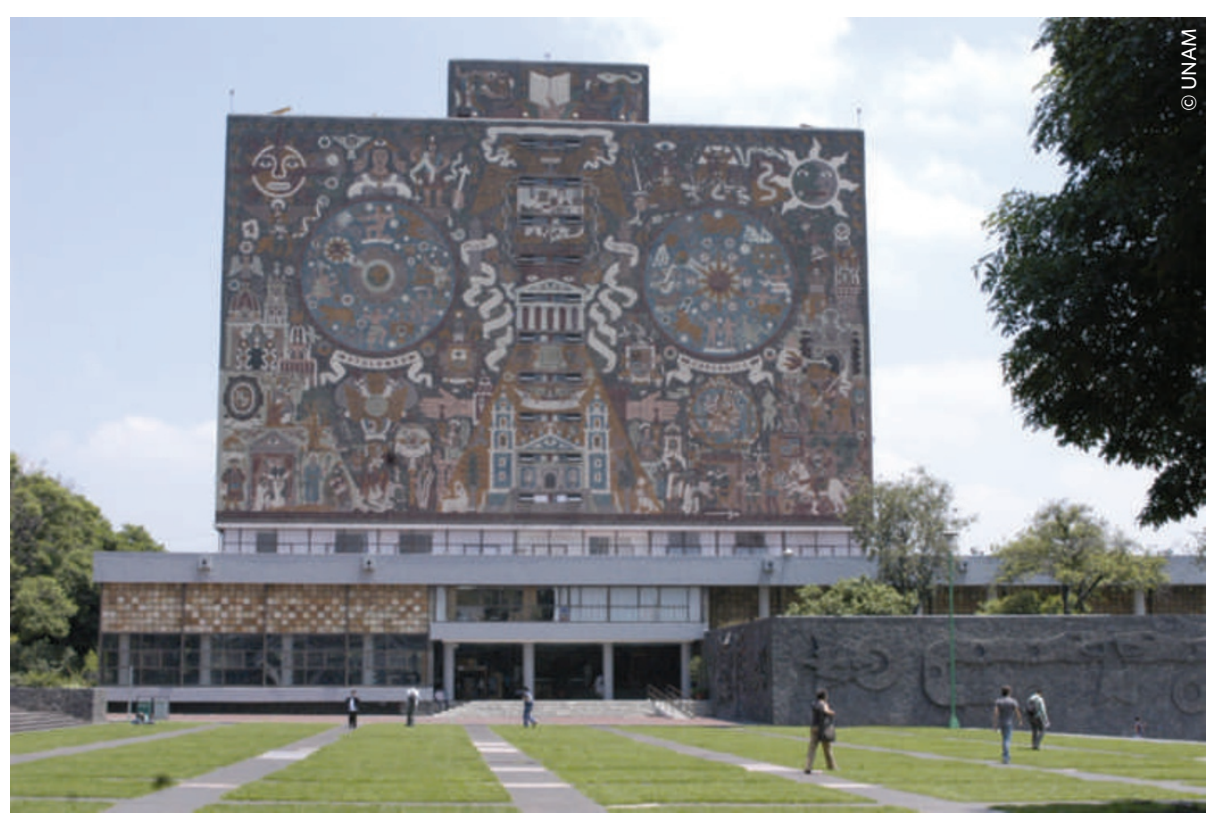

Figure 1 | The Central Library, National Autonomous University of Mexico (UNAM).

At that time, Mexican science experienced its second major breakthrough the synthesis by Luis Miramontes of norethindrone, a form of progesterone that is the basis of the contraceptive pill, marking the beginning of worldwide female liberation. One example of the Mexican government's enthusiasm for science and technology in the early 1970s was the creation of a Nuclear Research Centre equipped with a tandem Van de Graaf accelerator and a research nuclear reactor. Shortly after, Mexico acquired its only nuclear power plant, Laguna Verde. Simultaneously, an aggressive human resources programme was launched to solve the country's next problem: having very few people with a $\mathrm{PhD}$.

Efforts to improve this situation began with a successful, but modest, postgraduate scholarship programme with 200 grants per year, leading to the creation of the National Science and Technology Council (CONACYT) in 1970. Forty years later, this institution grants 24,000 postgraduate scholarships per year, 3,000 of which are for study abroad. The Council was also created to fund basic science and technological development projects. In 2007 its budget for science amounted to US\$70 million, in addition to US $\$ 400$ million authorized as tax-cut incentives for innovative research in industry.

A severe economic crisis in the early 1980s caused a drastic purchasing power reduction and initiated a brain drain that could only be stopped by the creation, in 1985, of the National Researchers System. The SNI, as it is called, eventually became a part of CONACYT and today grants 


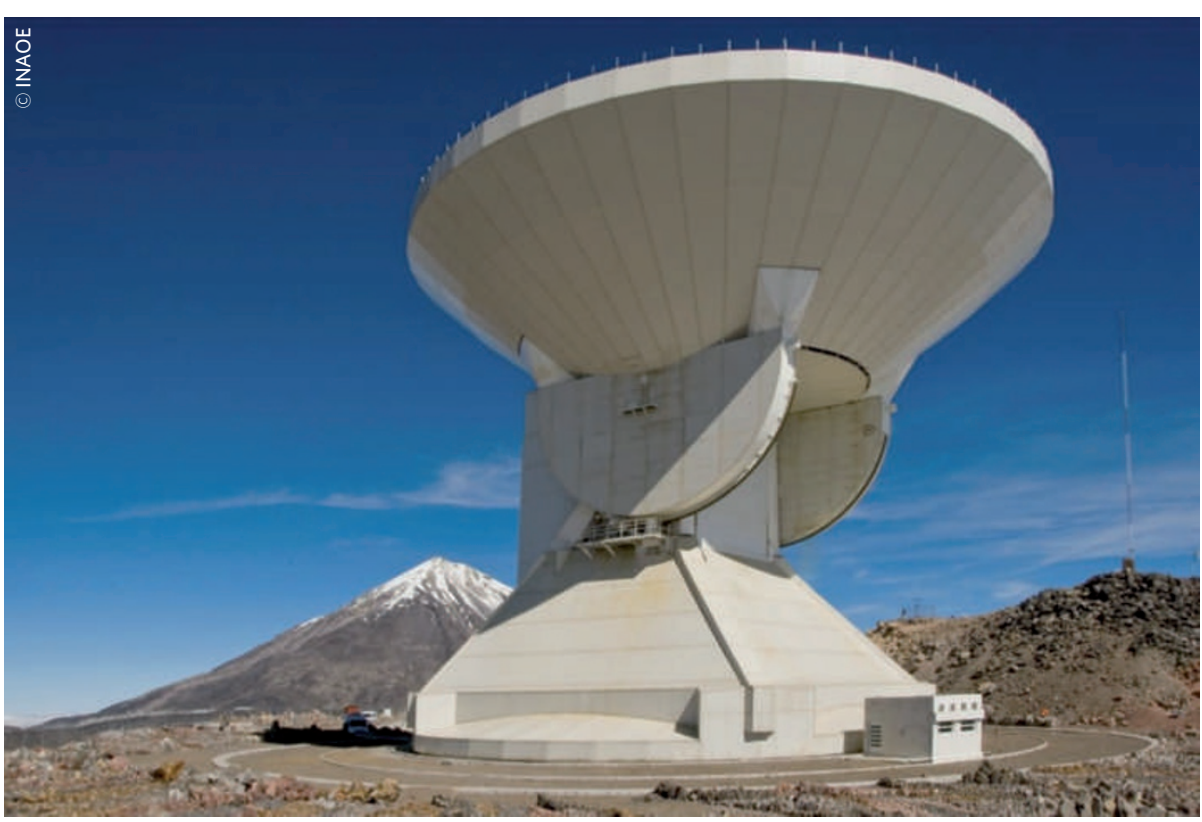

Figure 2 | The Large Millimetric Telescope, at Sierra Negra, Puebla, Mexico.

16,000 scholarships to active researchers. In 1992 the Council created a research programme for accredited institutions, which today include 27 different research centres around the country. In 2007, the Council devoted an annual budget of US\$450 million to this programme.

\section{An active scientific community}

Nowadays in Mexico research is being carried out in a broad spectrum of subjects. In astronomy, a field with millenary tradition in the country, there is a small but very active community of about 200 researchers, concentrated in just a few institutions of which UNAM and INAOE (a CONACYT Centre in the State of Puebla) are the most important. They operate several optical telescopes, the largest of which is located in San Pedro Mártir, Baja California. The most ambitious astronomical project in Mexico to date, the Large Millimeter Telescope (Fig. 2), is shared between INAOE and the University of Massachusetts. It costs over US\$120 million, and is installed at an altitude of 4,600 $\mathrm{m}$ at the top of the Sierra Negra extinct volcano.

In mathematics, there are 700 researchers holding a $\mathrm{PhD}$ in 27 institutions scattered throughout Mexico, although half are concentrated in just three of these: UNAM, the Metropolitan Autonomous University (UAM, Mexico's third largest university) and CIMAT, a CONACYT centre located in Guanajuato. In comparison, the physics community is about twice the size, with 1,300 researchers working in 70 institutions. The largest communities belong to UNAM, CINVESTAV (Center for Research and Advanced Studies, a prestigious institution based in Mexico City) and UAM. Most branches of physics are covered, with a focus on condensed matter, materials physics and optics. In some Mexican states, smaller groups have access to centralized instrument laboratories, whereas others gain access to them through national and international collaboration agreements. In this way, Mexican groups are part of most major international experiments carried out in Europe and the USA.

With a two million $\mathrm{km}^{2}$ territory and an 11,000 km-long coastline, Mexico has considerable natural wealth and is an interesting laboratory for earth science research, chiefly geology, oceanography and atmospheric sciences. The country has 27 research centres in this field and some $650 \mathrm{PhDs}$. Seismology and volcanology are important fields of research, as are exploration and mapping relating to oil prospective techniques. Climate change and the relationship between species extinction and the Chicxulub crater in the Yucatán Peninsula - produced by the impact of a massive meteor - are two other areas of activity in this field.

Mexico's territorial extension and contrasting relief, producing a widely varied climate, provide an enormous biological wealth. This is the laboratory for some 3,500 active researchers, working in areas related to biology and biomedicine.
Molecular biology and biotechnology are obviously important research fields. In agronomic sciences, a field in which 1,600 scientists are carrying out research, a strong basis was laid in the 1960s when Mexico saw the birth of what was later known as the Green Revolution. Initiated by Norman Bourlaug, an American geneticist who had lived in the country since 1944 and headed an internationally funded institution, the Green Revolution aimed to improve corn and wheat production. In 1970 Bourlaug was awarded the Nobel Peace Prize for introducing high-yield varieties and modern agricultural techniques.

In 1974 the Mexican scientist Mario Molina published an article in Nature highlighting the threat of chlorofluorocarbon gases to the Earth's protective ozone layer ${ }^{1}$, constituting the country's third scientific breakthrough, once again, in chemistry. In 1995, Mario Molina and his co-author Sherwood Rowland shared the Nobel Prize with atmospheric scientist Paul Crutzen. Molina is the first Mexican scientist to receive this prestigious award. Today, Mexico has 1,000 researchers in chemistry, spread over 72 institutions, of which UNAM has the largest share followed by UAM.

\section{Infrastructure problems}

Mexico has an estimated population of 108 million, the eleventh highest worldwide; a gross domestic product of 875 billion US dollars (14th worldwide); and foreign exchange reserves ranking 17 th worldwide (the UK's is ranked 25th). The Times University Ranking 2009 placed UNAM as the first in Latin America. In the last decade the country has undergone rapid changes, moving from a relatively closed economy to an open one, and from a one-party political system to a more democratic one. Given these developments, together with the current international economic crisis and the many local problems (the $2009 \mathrm{AH} 1 \mathrm{~N} 1$ pandemic influenza and severe drug-dealing-related security concerns in particular), Mexico's economy is coping relatively well.

Across all disciplines, the country's scientific community has over 40,000 members, $40 \%$ of which are SNI members and therefore active researchers. Half of the latter obtained their PhDs in Mexico, reflecting the ability of the system to reproduce itself. In 2007, Mexican scientists published or co-authored some 7,000 papers indexed by the ISI Web of Knowledge database, representing $0.7 \%$ of the total world's production, compared with Mexico's share of $1.6 \%$ of the global population. However, its scientific output 
places Mexico as 23rd in the world rankings concerning scientific productivity and 24 th for relative impact measured by the h-index.

This low position is in part a consequence of Mexico being second-last among the Organization for Economic Cooperation and Development (OECD) countries when considering government spending in science $(0.36 \%$ of the gross national product), and last in the number of scientists per capita. The latter is probably related to a failure in the country's capacity to incorporate the people it is training into the science and technology system. Between 1994 and 2007 as many students obtained a PhD in the country as the total number of SNI members today, indicating that half of these graduates did not find an opportunity to continue research in Mexico.

The situation is also delicate when one considers that Mexico (together with Turkey) is placed last in the OECD ranking for elementary school children's science performance. Once again, this relates to the country's education investment being only a quarter of the OECD average. In addition to this underfunding of the sciences, other problems affecting Mexican science are the centralization of the research infrastructure (40\% of SNI researchers live in Mexico City) and gender inequality (only about $30 \%$ of SNI members are women).

A further key aspect affecting Mexican science is the technological development. Technology has played a crucial role in defining the country's destiny, beginning as far back as the unfair gold-by-marbles exchange between Indians and Conquistadores. In colonial times, Spanish interests played against the development of a strong research infrastructure, as illustrated by the fact that the scientists whom Humboldt met in 1803 had no independent means to confirm del Rio's findings.

Unfortunately, two centuries later Mexican science continues to rely on commercial, imported equipment. In September 2005, an editorial in Nature Medicine caused outrage in the Mexican scientific community, which in the text was accused of engaging in 'me-too' science rather than developing its own original ideas ${ }^{2}$. Although the statement is unfair if interpreted as an intended policy, one has to admit that relying solely on commercial equipment severely reduces the grounds for original observations. Experimental science is nowadays so competitive that those who succeed in observing new phenomena, more often than not do so using either entirely original laboratory instrumentation, or commercial ones coupled to original accessories.

So what is preventing Mexico from developing its own original equipment? The answer is complex, but the main ingredients are insufficient financial support and an insensitive scientific-project evaluation system. The result is a country engaged in scientific projects that can be carried out with modest equipment rarely reaching value beyond US $\$ 100,000$. The only alternative to this is to buy or, at best, integrate equipment. Unfortunately, an insufficient research infrastructure means that not only scientists, but also technologists and enterprises have become increasingly addicted to buying rather than developing technology. As a consequence, Mexico's purchasing of high-technology goods increased by one order of magnitude over the past decade. In the same period, their royalty payments for technology increased by a factor of five, while their own royalty revenues are now half of what they were.

\section{Mexico cannot go on ignoring recommendations to significantly increase public investment in science and technology and improve its archaic education system.}

A related problem is the severe lack of initiative on the part of Mexicans to produce patents. Although the number of patents registered in Mexico every year is increasing steadily, now exceeding 10,000 , the number of patents registered by Mexican nationals has been stuck at about 200 per year for decades. The Mexican Government, presumably aware of this situation, has implemented (via CONACYT) tax incentives and funding for research collaborations between industry and public research centres to promote research in industry. Unfortunately, so far there have been few signs of success. Without an aggressive science and technology policy, Mexico is becoming increasingly dependent on manual labour and the export of natural resources.

Mexico has a small, but enthusiastic scientific community, working in important subjects and producing results with sufficient success, given the level of investment. Leaders of this group are admitted to the Mexican Academy of Sciences (AMC), which today has 2,168 Regular Members and 100 Corresponding Members, including 10 Nobel Laureates. In addition to other academic distinctions, the Academy awards the most prestigious Mexican science award for young researchers.

Aware of the severe science-education problems facing the country, the AMC also runs a number of programmes directed at raising the level of elementaryschool science teaching as well as increasing the interest in science amongst the Mexican youth. Actions include the training of elementary school teachers, popular science talks in communal centres throughout the country, a scholarship programme to finance summer visits with active researchers for over 1,000 undergraduate students, olympiads for children in various science and humanities fields, courses in computer education for children, and so on. The Academy also publishes a science popularization journal, Ciencia, as well as a number of books every year. The Academy represents Mexican science nationally and internationally, and runs scientific networks on a number of sensitive subjects, such as biotechnology, bioethics and water. As well as continuing to support all these activities, the work plan of the recently installed Executive Board aims to increase the promotion of science among adults and improve links with the government, industry and other science and technology-promoting organizations.

Mexico faces the enormous challenge of creating the virtuous circle that links science and technology with the economy of the country and the wellbeing of its inhabitants. This can only be achieved through a coordinated effort between government, industry and academia to produce, and implement a national strategy towards a knowledge-based economy. Mexico cannot go on ignoring OECD recommendations to significantly increase public investment in science and technology and improve its archaic education system. The AMC and industry also have the obligation to build the mutual trust needed for a brighter economic future.

Arturo Menchaca-Rocha is President of the Mexican Academy of Sciences, Calle Cipreses $s / n$, San Andrés Totoltepec, Tlalpan, 14400 D.F., Mexico. e-mail: menchaca@fisica.unam.mx

\section{References}

1. Molina, M. J. \& Rowland, F. S. Nature 249, 810-812 (1974) 2. Editorial. Nature Med. 11, 907 (2005). 